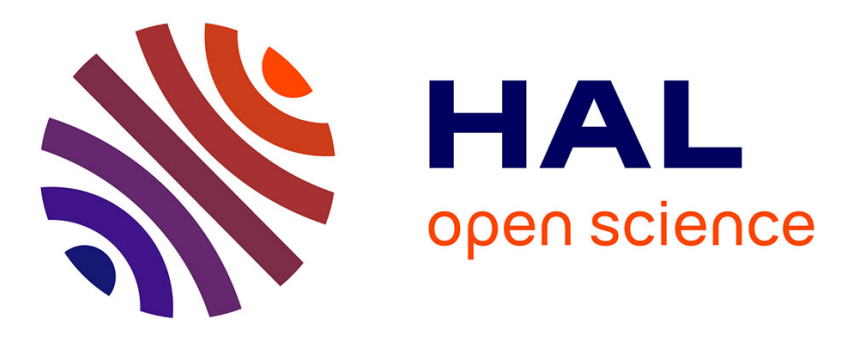

\title{
Diluted Fe3+ in silicate glasses: Structural effects of Fe-redox state and matrix composition. An optical absorption and X-band/Q-band EPR study
}

Vincent Vercamer, Gérald Lelong, Hiroyuki Hijiya, Yuki Kondo, Laurence Galoisy, Georges Calas

\section{To cite this version:}

Vincent Vercamer, Gérald Lelong, Hiroyuki Hijiya, Yuki Kondo, Laurence Galoisy, et al.. Diluted Fe3+ in silicate glasses: Structural effects of Fe-redox state and matrix composition. An optical absorption and X-band/Q-band EPR study. Journal of Non-Crystalline Solids, 2015, pp.138-145. 10.1016/j.jnoncrysol.2015.08.010 . hal-01198781

\section{HAL Id: hal-01198781 \\ https: / hal.sorbonne-universite.fr/hal-01198781}

Submitted on 14 Sep 2015

HAL is a multi-disciplinary open access archive for the deposit and dissemination of scientific research documents, whether they are published or not. The documents may come from teaching and research institutions in France or abroad, or from public or private research centers.
L'archive ouverte pluridisciplinaire HAL, est destinée au dépôt et à la diffusion de documents scientifiques de niveau recherche, publiés ou non, émanant des établissements d'enseignement et de recherche français ou étrangers, des laboratoires publics ou privés. 


\title{
Diluted $\mathrm{Fe}^{3+}$ in silicate glasses: structural effects of Fe-redox state and matrix composition. An optical absorption and X-band/Q-band EPR study
}

\author{
Vincent Vercamer, ${ }^{\mathrm{a}, \mathrm{c}, \dagger}$ Gérald Lelong, ${ }^{\mathrm{a}, \dagger}$ Hiroyuki Hijiya ${ }^{\mathrm{b}}$, Yuki Kondo ${ }^{\mathrm{b}}$, Laurence Galoisy ${ }^{\mathrm{a}}$, \\ Georges Calas $^{\mathrm{a}}$
}

\begin{abstract}
${ }^{\text {a }}$ Institut de Minéralogie, de Physique des Matériaux, et de Cosmochimie (IMPMC) - Sorbonne Universités - UPMC Univ Paris 06, UMR CNRS 7590, Muséum National d'Histoire Naturelle, IRD UMR 206, 4 Place Jussieu, F-75005 Paris, France.

${ }^{\mathrm{b}}$ Research Center, Asahi Glass Co. Ltd., 1150 Hazawa-cho, Kanagawa-ku, Yokohama 221-8755, Japan.
\end{abstract}

${ }^{\mathrm{c}}$ AGC France SAS, 100 rue Léon Gambetta, 59168 Boussois, France.

\begin{abstract}
Sodium-alkaline earth-silicate glasses, of nominal molar composition $16 \mathrm{Na}_{2} \mathrm{O}-10 \mathrm{RO}-74 \mathrm{SiO}_{2}$ $(\mathrm{R}=\mathrm{Ca}$, $(\mathrm{Ca}, \mathrm{Mg})$ and $\mathrm{Mg})$ doped with $0.5 \mathrm{wt} \%$ of $\mathrm{Fe}_{2} \mathrm{O}_{3}$, were studied by UV-Visible-NIR absorption spectroscopy and electron paramagnetic resonance (EPR) at X- and Q-band to understand the structural control of $\mathrm{Fe}^{3+}$ optical absorption properties as a function of iron redox and glass composition. By comparing with a set of ${ }^{[4]} \mathrm{Fe}^{3+},{ }^{[5]} \mathrm{Fe}^{3+}$ and ${ }^{[6]} \mathrm{Fe}^{3+}$ crystalline references, optical absorption spectra indicate the presence of 5-fold $\mathrm{Fe}^{3+}$ in addition to a majority of tetrahedral $\mathrm{Fe}^{3+}$. The combination of Q- and X-band EPR data shows $\mathrm{Fe}^{3+}$ partition among isolated, distributed sites and Ferich clusters, providing unique insight into the distortion of isolated $\mathrm{Fe}^{3+}$ sites. It demonstrates also the peculiar character of the residual $\mathrm{Fe}^{3+}$ sites that exist in reduced glasses. Changing $\mathrm{Ca}$ to $\mathrm{Mg}$ increases the amount of tetrahedral $\mathrm{Fe}^{3+}$ sites and decreases their distortion. The presence of $\mathrm{Mg}$ also reduces the amount of isolated rhombic $\mathrm{Fe}^{3+}$ sites and promotes the formation of clusters. These clusters confirm the non-homogeneous structure of silicate glasses, as well as the preference of $\mathrm{Fe}^{3+}$ for a more calcic than magnesian environment in sodic $(\mathrm{Ca}, \mathrm{Mg})$ glasses.
\end{abstract}

Keywords: iron redox; clustering; optical absorption spectroscopy; X-band/Q-band EPR/ESR; site distortion

\footnotetext{
†Corresponding author: gerald.lelong@impmc.upmc.fr or vincent.vercamer@upmc.fr
} 


\section{Introduction}

Iron, an impurity encountered in most industrial glasses, may be used to control glass coloration and to give rise to functional glasses, by controlling energy transmission and thermal insulation. Understanding the influence of $\mathrm{Fe}$ on glass properties may then help develop innovative functional glasses. Iron usually occurs under two oxidation states $\mathrm{Fe}^{2+}$ (ferrous) and $\mathrm{Fe}^{3+}$ (ferric). The relative proportion of these two oxidation states defines the redox state of iron $\left(\mathrm{R}=\mathrm{Fe}^{2+} / \mathrm{Fe}_{\mathrm{tot}}\right)$. $\mathrm{R}$ is a function of glass composition, elaboration temperature and oxygen fugacity.[1-3] Ferrous and ferric ions are localized in specific environments within glass structure, giving diluted glasses a blue $\left(\mathrm{Fe}^{2+}\right)$, yellow $\left(\mathrm{Fe}^{3+}\right)$ or green (mixed oxidation states) color. Ultraviolet-Visible-Near-Infrared (UV-Visible-NIR) spectroscopy provides a direct correlation between the colorimetric properties of transition metalcontaining glasses through their transmittance functions, and the structural surrounding of these transition elements, through the sensitivity of optical absorbance functions to crystal field effects, charge-transfer transitions or magnetic coupling.[4] Optical absorption spectroscopy has been used to study Fe-speciation and redox properties in glasses.[5-7]

Among transition elements, optical properties of $\mathrm{Fe}^{3+}$ in glasses are still a matter of discussion, due to the low intensity of their spin-forbidden optical transitions and the field-independent character of the most intense transitions. In addition, these transitions are superimposed either to the tail of $\mathrm{Fe}^{2+}$ bands in the visible range (at least 10 times more intense) or to the tail of the oxygen to metal charge transfer (OMCT) transitions (100 to 1000 more intense) in the near UV. In a sodium-silicate glass with higher than $3 \mathrm{wt} \% \mathrm{Fe}_{2} \mathrm{O}_{3}, \mathrm{Fe}^{3+}$ is not only in tetrahedral sites $\left({ }^{[4]} \mathrm{Fe}^{3+}\right), \sim 30 \%$ of ferric ions are in a higher coordination. [8] The presence of higher coordinated $\mathrm{Fe}^{3+}$ in glasses has been deduced from Xray absorption spectroscopy, neutron diffraction and numerical simulation studies [9-12] although, their influence on optical absorption spectra in iron-doped glasses is still speculative.

Since the pioneering work of Castner et al. [13], electron paramagnetic resonance (EPR) has proven to be a sensitive technique to probe the environment of $\mathrm{Fe}^{3+}$ in glasses (the short spin-lattice relaxation time of $\mathrm{Fe}^{2+}$ precludes direct observation of $\mathrm{Fe}^{2+}$ in glasses with conventional EPR). The Xband EPR spectrum of $\mathrm{Fe}^{3+}$ in silicate glasses is characterized by an asymmetric signal at $\mathrm{g}=4.3^{*}$, accompanied by two weaker features near $\mathrm{g}=8$ and $\mathrm{g}=2$. The resonances at $\mathrm{g}=4.3$ and $\mathrm{g}=8$ originate from paramagnetic transitions of isolated $\mathrm{Fe}^{3+}$ ions in rhombic $\left(\mathrm{C}_{2 \mathrm{v}}\right.$ with $\left.\mathrm{E} / \mathrm{D} \sim 1 / 3\right)$ and axially (E/D $\sim$ ) distorted sites, respectively.[14-16] The attribution of the feature at $g=2$ is less clear.[17] Different scenarios have been proposed: (i) a signal due to exchange-coupled pairs or clusters of more than two atoms[18] involving edge- or face-sharing $\mathrm{Fe}^{3+}$ sites $[16,19,20]$. These clusters could be trimers [21] up to nano-clusters as in ferritine[22], nanoparticles[23] or obsidian

wt. $\%$ 
glasses[7,24]; (ii) a paramagnetic signal due to $\mathrm{Fe}^{3+}$ in axially distorted sites $(\mathrm{E} / \mathrm{D} \sim 0)[19]$, this signal being enhanced by dipole-dipole interactions.[25] The proportion of these two overlapping contributions depends on glass composition and Fe-redox state.[16,26] The $g=2$ signal can also be assigned to $\mathrm{Fe}^{3+}$ in regular site with high symmetry, e.g. tetrahedral or octahedral[15,27]. However, this latter interpretation is not coherent with the long tail above $350 \mathrm{mT}$ that goes back to 0 around $600 \mathrm{mT}$. Low-temperature EPR measurements have shown the presence of paramagnetic clusters in Fe-doped borate glasses, because small clusters exhibit an antiferromagnetic behavior, whereas the EPR signal of diluted $\mathrm{Fe}^{3+}$ exhibits a paramagnetic behavior.[28] Thus, the disappearance of the $\mathrm{g}=2$ signal when temperature decreases is used as evidence of the presence of $\mathrm{Fe}^{3+}$ containing clusters, as observed in ferritin [22] or nanoparticles[23].

The aim of this study is to improve our understanding of the local environment of $\mathrm{Fe}^{3+}$ in silicate glasses at low $\mathrm{Fe}^{3+}$ concentration and interpret the origin of the most important $\mathrm{Fe}^{3+}$ optical transitions by comparing variable temperature EPR spectroscopy with optical absorption spectroscopy of glasses and crystalline references. We report the first Q-band EPR data on $\mathrm{Fe}^{3+}$ in silicate glasses, showing that $\mathrm{Fe}^{3+}$ site distortion is limited. Regarding the results, the presence of $\mathrm{Fe}^{3+}$-containing clusters varies with redox and composition and seems to do not affect the optical absorption. Moreover, $\mathrm{Fe}^{3+}$ shows a structural and chemical preference for larger alkaline earth environment.

\section{Experimental details}

\subsection{Sample preparation}

Three series of silicate glasses containing $0.5 \mathrm{wt} \%$ of $\mathrm{Fe}_{2} \mathrm{O}_{3}$ were prepared using reagent-grade materials $\left(\mathrm{Fe}_{2} \mathrm{O}_{3}, \mathrm{SiO}_{2}, \mathrm{Na}_{2} \mathrm{CO}_{3}, \mathrm{MgO}\right.$ and $\left.\mathrm{CaCO}_{3}\right)$ with the nominal molar compositions $16 \mathrm{Na}_{2} \mathrm{O}-$ $x \mathrm{CaO}-(10-x) \mathrm{MgO}-74 \mathrm{SiO}_{2}(x=0,5,10)$. They will be denoted as NMS05-X, NCMS05-X and NCS05$\mathrm{X}$, respectively. $\mathrm{X}$ describes the redox state $\mathrm{R}=\mathrm{Fe}^{2+} / \mathrm{Fe}_{\text {tot }}$ : Med for medium $(\mathrm{R} \approx 25 \%)$, Red for reduced $(\mathrm{R} \approx 99 \%)$, and $\mathrm{Ox}$ for oxidized $(\mathrm{R} \approx 5 \%)$. The redox was adjusted using three experimental protocols:

- Normal conditions (Med) - R $\approx 25 \%: 400 \mathrm{~g}$ of batch was melted and stirred at $1500^{\circ} \mathrm{C}$ for $1 \mathrm{~h}$ in a Pt crucible under air atmosphere. Samples were poured and quenched onto preheated plates, annealed at $580^{\circ} \mathrm{C}$ for $1 \mathrm{~h}$ to release internal stresses, and finally cooled down to room temperature at $1{ }^{\circ} \mathrm{C} / \mathrm{min}$.

- Reducing conditions (Red) - $\mathrm{R} \approx 99 \%: 20 \mathrm{~g}$ of batch was melted at $1500^{\circ} \mathrm{C}$ for $1 \mathrm{~h}$ in a carbon crucible under $\mathrm{N}_{2}$ atmosphere. Glasses were not annealed to avoid oxidation.

- Oxidizing conditions $(\mathrm{Ox})-\mathrm{R} \approx 5 \%$ : $5 \mathrm{~g}$ of batch was melted at $1200^{\circ} \mathrm{C}$ at $200^{\circ} \mathrm{C} / \mathrm{h}$ in a Pt crucible, under $\mathrm{O}_{2}$ atmosphere, then kept at $1200^{\circ} \mathrm{C}$ for $2 \mathrm{~h}$ and cooled down at $150^{\circ} \mathrm{C} / \mathrm{h}$. Glasses were not annealed to avoid reduction. 
The amount of $\mathrm{Fe}^{2+}$ and total iron was determined by wet chemical analysis based on standard test method [29] using the absorption band of the complex formed between o-phenanthroline and $\mathrm{Fe}^{2+}$ at $510 \mathrm{~nm}$. The measured redox states are presented in Table 1. The vitreous nature of the glasses was checked using X-ray diffraction. Sample homogeneity was checked using an electron probe microanalyzer (CAMECA SXFive) at the Camparis Facility (Université Pierre et Marie Curie, Paris, France). Analyses were made with a $15 \mathrm{kV}$ accelerating voltage and a $4 \mathrm{nA}$ sample current. Actual and nominal compositions (in wt \%) are shown in Table 2.

\subsection{Optical absorption spectroscopy}

Optical absorption spectroscopy was carried out using a Perkin-Elmer ${ }^{\circledR}$ Lambda 1050 UV-VisibleNIR spectrophotometer in transmission mode in the range $196-3333 \mathrm{~nm}\left(51000-3000 \mathrm{~cm}^{-1}\right)$. Double-sided polished samples $(2.5 \mathrm{~mm}$ thick) were used. In order to estimate the absorption background related to reflection phenomena on surfaces, 2.5 and $5.5 \mathrm{~mm}$ thick samples were measured for the three compositions NCS05-Med, NCMS05-Med and NMS05-Med. The absorption difference gives the equivalent spectrum of a $3 \mathrm{~mm}$ thick sample corrected from reflection. The intensity of $\mathrm{Fe}^{3+}$ bands was measured after the removal of the UV edge using two Gaussian curves. The procedure explained in [30] was used from 27500 to $31000 \mathrm{~cm}^{-1}$ in order to fit the tail of the OMCT bands before absorbance saturation. The fitted $\mathrm{Fe}^{3+}$ bands (above $20000 \mathrm{~cm}^{-1}$ ) are not influenced by the $\mathrm{Fe}^{2+}$ tail (below $20000 \mathrm{~cm}^{-1}$ ).

\subsection{Electron paramagnetic resonance (EPR) spectroscopy}

EPR spectra were measured using a Bruker ESP300 spectrometer at X-band $(9.5 \mathrm{GHz})$ and Q-band (34 GHz), with a field modulation of $100 \mathrm{kHz}$ and an amplitude modulation of $1 \mathrm{mT}$. Lowtemperature measurements were carried out using helium Oxford cryostats allowing measurements down to $4 \mathrm{~K}$. Samples were machined to have a cylindrical form: $15 \mathrm{~mm}$ long by about $2 \mathrm{~mm}$ diameter for X-band and $2 \mathrm{~mm}$ long by $1.5 \mathrm{~mm}$ diameter for Q-band. Samples were placed in pure silica tubes (Suprasil) for X-band or stuck on a pure silica rod for Q-band. The measurements were performed at different microwave power to adjust a convenient signal to noise ratio without saturation phenomena. EPR X-band spectra were normalized to sample mass, gain, amplitude modulation and square root of power (in $\mathrm{mW}$ ).

\section{Results and discussion}

\subsection{Optical absorption spectroscopy}

The shape and position of the main $\mathrm{Fe}^{3+}$ bands (near 22800, 24000 and $26300 \mathrm{~cm}^{-1}$ ) are similar in NCS05-Med and NCS05-Ox together with a weak and broad band at around 20500-21200 $\mathrm{cm}^{-1}$ (Figure 1). After removal of the OMCT edge, a Gaussian fit of the NCS05-Ox spectrum (Figure 2 and Table 3) was performed by comparison with three $\mathrm{Fe}^{3+}$-bearing crystalline references: (1) $\mathrm{Fe}$ orthoclase [4,31], with substituted 4 -fold $\mathrm{Fe}^{3+}$ in a tetrahedral site, (2) yoderite[32,33], a 5-fold $\mathrm{Fe}^{3+}$ 
bearing mineral and (3) andradite[4,34], a 6-fold $\mathrm{Fe}^{3+}$ bearing garnet.

According to the transitions observed in crystalline references (Table 4), the three resolved bands at around 22800,24000 and $26300 \mathrm{~cm}^{-1}$ are commonly assigned to tetrahedral ${ }^{[4]} \mathrm{Fe}^{3+}$.[30] However, a good fit may only be obtained with at least three additional contributions at around 21200, 25500 and $27200 \mathrm{~cm}^{-1}$, otherwise Gaussian shape residuals are present at these positions. A weak contribution at around $27200 \mathrm{~cm}^{-1}$ can be attributed to uncertainties related to edge subtraction. The band at around $25500 \mathrm{~cm}^{-1}$, which has a similar absorbance as the bands at 22800 and $24000 \mathrm{~cm}^{-1}$, is absent from optical spectra of Fe-orthoclase $\left({ }^{[4]} \mathrm{Fe}^{3+}\right)$ or andradite $\left({ }^{[6]} \mathrm{Fe}^{3+}\right)$. Moreover, the important integrated area is indicative of a non-centrosymmetric site, such as in ${ }^{[5]} \mathrm{Fe}^{3+}$, which is consistent with the position and intensity of the ${ }^{6} \mathrm{~A}_{1}(\mathrm{~S}) \rightarrow{ }^{4} \mathrm{~T}_{2}(\mathrm{D})$ transition of ${ }^{[5]} \mathrm{Fe}^{3+}$ in yoderite (Table 4).[32] The correspondence of this band between glass and mineral supports the existence of 5 -fold $\mathrm{Fe}^{3+}$ in glasses.

The contribution around 20500-21200 $\mathrm{cm}^{-1}$ has been assigned to the ${ }^{6} \mathrm{~A}_{1}(\mathrm{~S}) \rightarrow{ }^{4} \mathrm{~T}_{2}(\mathrm{G})$ transition of tetrahedral $\mathrm{Fe}^{3+}$.[35] For the glasses under investigation, this band is broader than in Fe-orthoclase and no decrease of the absorbance is observed between the signal at $20500 \mathrm{~cm}^{-1}$ and the band at $22800 \mathrm{~cm}^{-}$ ${ }^{1}$. This can be explained by the overlapping of absorption bands of higher coordinated $\mathrm{Fe}^{3+}$, such as ${ }^{[5]} \mathrm{Fe}^{3+}$, whose bands at 20700 and $21500 \mathrm{~cm}^{-1}$ in yoderite are assigned to the transition ${ }^{6} \mathrm{~A}_{1} \rightarrow\left[{ }^{4} \mathrm{~A}_{1}\right.$, $\left.{ }^{4} \mathrm{E}(\mathrm{G})\right]$.[32] The optical evidence of ${ }^{[5]} \mathrm{Fe}^{3+}$ in glasses may indicate a $\mathrm{Fe}^{3+}$-site distribution from 4- to 5coordinated sites, as shown for $\mathrm{Fe}^{2+} \cdot[36,37]$

However, there is no evidence of 6 -fold coordinated $\mathrm{Fe}^{3+}$ in the investigated glasses in the 12000 $17000 \mathrm{~cm}^{-1}$ range expected for the crystal field dependent transitions of ${ }^{[6]} \mathrm{Fe}^{3+}\left({ }^{6} \mathrm{~A}_{1 \mathrm{~g}}(\mathrm{~S}) \rightarrow{ }^{4} \mathrm{~T}_{1 \mathrm{~g}}(\mathrm{G})\right.$ and ${ }^{6} \mathrm{~A}_{1 \mathrm{~g}}(\mathrm{~S}) \rightarrow{ }^{4} \mathrm{~T}_{2 \mathrm{~g}}(\mathrm{G})$ as in andradite: Table 4). In this range, there is no significant contribution superimposed to the tail of $\mathrm{Fe}^{2+}$ absorption band. The presence of ${ }^{[4]} \mathrm{Fe}^{3+}$ and ${ }^{[5]} \mathrm{Fe}^{3+}$ is sufficient to account for the visible-UV transitions between 20000 and $26000 \mathrm{~cm}^{-1}$. In this range, optical absorption bands of ${ }^{[6]} \mathrm{Fe}^{3+}$ occur almost at the same positions as 4 - and 5-fold coordinated $\mathrm{Fe}^{3+}$ with similar intensities. By contrast, band intensity is expected to be weak in the absence of a $3 \mathrm{~d}-4 \mathrm{p}$ hybridization for centrosymmetric geometries such as $\mathrm{O}_{\mathrm{h}}, \mathrm{D}_{4 \mathrm{~h}}$ or axially strained site geometries as in andradite $\left(\mathrm{C}_{3 \mathrm{i}}\right)$ (see [38] and references therein).

The spectrum of NCS05-Red (Figure 1) does not show evidence of $\mathrm{Fe}^{3+} \mathrm{d}-\mathrm{d}$ transitions: the band at $26300 \mathrm{~cm}^{-1}$ is not discernible, even after the UV edge removal. The absence of $\mathrm{Fe}^{3+}$ bands confirms the high $\mathrm{Fe}^{2+} / \mathrm{Fe}_{\text {tot }}$ ratio $(\mathrm{R}=99 \%)$. In the spectral region of interest for $\mathrm{Fe}^{3+}$, i.e. between 18000 and $28000 \mathrm{~cm}^{-1}$, the background is slightly higher than in the NCS05-Ox and two weak bands are visible around 21500 and $23400 \mathrm{~cm}^{-1}$. These two weak bands, which can not be ascribable to residual $\mathrm{Fe}^{3+}$ (the $\mathrm{Fe}^{3+}$ concentration is estimated here at $\sim 50 \mathrm{ppm}$ ), are assigned to the $\mathrm{Fe}^{2+}$ spin-forbidden transitions ${ }^{5} \mathrm{~T}_{2}(\mathrm{D}) \rightarrow{ }^{3} \mathrm{~T}_{1}(\mathrm{H})$ and ${ }^{5} \mathrm{~T}_{2}(\mathrm{D}) \rightarrow{ }^{3} \mathrm{~T}_{2}(\mathrm{H})$ as suggested in $\mathrm{Fe}^{2+}\left(\mathrm{H}_{2} \mathrm{O}\right)_{6}$ [4] and in a sodiumalkaline earth silicate glass.[39] Grandidierite $\left({ }^{[5]} \mathrm{Fe}^{2+}\right)$ shows similar weak features between 20000 and 
$25000 \mathrm{~cm}^{-1} \cdot[40,41]$ Our measurements suggest that the background of the optical spectra of reduced silicate glasses containing iron is constituted by a succession of poorly resolved bands with low intensities related to $\mathrm{Fe}^{2+}$ spin-forbidden transitions that could lead to overestimate the background if the minimum of the spectrum around $18000 \mathrm{~cm}^{-1}$ is considered as the background value.

The Ca:Mg ratio influences the optical absorption spectra as shown in Figure 3. When replacing Ca by $\mathrm{Mg}$, the background-subtracted $\mathrm{Fe}^{3+}$ spectra keep a similar shape, the NCMS05-Med spectrum being closer to NCS05-Med rather than to NMS05-Med. At the same time, the $26300 \mathrm{~cm}^{-1}$ and $25500 \mathrm{~cm}^{-1}$ bands become more intense and weaker, respectively. This could arise from an increasing proportion of ${ }^{[4]} \mathrm{Fe}^{3+}$ in the oxidized and medium Mg-rich samples (NMS) compared to Ca-rich samples (NCS).

\subsection{X-band electron paramagnetic resonance (EPR) spectroscopy}

NCS05-Med and -Ox glasses give typical EPR signals for a $\mathrm{Fe}^{3+}$-bearing glass (Figure 4) with two main lines at $160 \mathrm{mT}(\mathrm{g}=4.3)$ and at $340 \mathrm{mT}(\mathrm{g}=2)$ characteristic of the site repartition presented in the introduction. However, NCS05-Red (50 $\mathrm{ppm} \mathrm{Fe}^{3+}$ ) gives rise to a peculiar EPR signal (Figure 4) with (i) a zero field signal, (ii) a sloping background below $100 \mathrm{mT}$, (iii) a weak signal at $\mathrm{g}=8$ (around $80 \mathrm{mT}$ ), (iv) appearance of shoulders just before and after the $\mathrm{g}=4.3$ line (at $130 \mathrm{mT}$ and 170 $\mathrm{mT}$ ), and (v) a split signal at $\mathrm{g}=4.3$ (See the inset of Figure 4). Moreover, two signals are superimposed at $\mathrm{g}=2$ : a wide signal (marked $\mathrm{A}$ in Figure 4) related to clustering of $\mathrm{Fe}^{3+}$ ions and a sharp one at $350 \mathrm{mT}$ (marked B in Figure 4) related to defects trapped on silicate groups that will not be studied here. The split signal at $\mathrm{g}=4.3$ observed in the reduced samples is due to the separation of the three EPR Kramer's doublet transitions $d_{x x}, d_{y y}$ and $d_{z z}$, which are not overlapping each other. This unusual splitting indicates that the distribution of the isolated $\mathrm{Fe}^{3+}$ sites is relatively narrow and does not include sites with a pure rhombic distortion. By contrast, in oxidized samples, $\mathrm{Fe}^{3+}$ (>1000 ppm) the broad site distribution among different site geometries includes sites with rhombic distortion, which is consistent with optical spectroscopy. Site geometry does depend on $\mathrm{Fe}^{3+}$ concentration: in that sense, residual $\mathrm{Fe}^{3+}$ appears to probe the specific ("defective") sites of the structure of reduced glasses, as it probes an average local structure broader site distribution at higher concentration.

\subsection{Low-temperature X-band EPR}

The EPR spectrum of NCS05-Red at 4K (Figure 5) shows an intense and broad line centered on 60 $\mathrm{mT}$ ( $\mathrm{g} 13$ ), which follows a Curie's law ( $\mathrm{I}_{\mathrm{pp}}$ is proportional to $1 / \mathrm{T}$ ). This signal may be caused by a ferromagnetic resonance due to traces of metallic Fe [16], and is at the origin of the zero field signal and the sloping background observed at room temperature (Figure 4). The $g=4.3$ line is narrower at $4 \mathrm{~K}$ than at room temperature and shows a shoulder at $170 \mathrm{mT}$. The $\mathrm{g}=2$ signal for both NCS05-Med and NCS05-Ox keeps the same shape at low temperature but the $\mathrm{g}_{4.3} / \mathrm{g}_{2}$ ratio is two times higher than at room temperature. For NCS05-Red, the $g=2$ line (marked A in Figure 4) is wider $\left(\Delta \mathrm{H}_{\mathrm{pp}} \sim 60 \mathrm{mT}\right)$ than in NCS05-Med and NCS05-Ox $\left(\Delta \mathrm{H}_{\mathrm{pp}} \sim 25 \mathrm{mT}\right)$. These observations confirm a modification of the 
$\mathrm{Fe}^{3+}$ site repartition as a function of the redox state of the glass. As the intensity of the signal at $\mathrm{g}=2$ line disappears on the EPR spectra of NCS05-Red when temperature is lowered to $4 \mathrm{~K}$, this signal is assigned to the presence of $\mathrm{Fe}^{3+}$ clusters, with $\mathrm{Fe}^{3+}-\mathrm{Fe}^{3+}$ and/or $\mathrm{Fe}^{3+}-\mathrm{Fe}^{2+}$ magnetic coupling becomes insignificant in comparison with the increase of the paramagnetic effect of isolated iron in regular sites at $\mathrm{g}=4.3 \cdot[5,15-17,28,42-46]$

\subsection{Low-temperature Q-band EPR}

To our knowledge, Q-band EPR spectra have not been investigated in silicate glasses despite a higher microwave frequency may help in assessing the rhombic distortion of the $\mathrm{Fe}^{3+}$ site. Q-band (34 Ghz) EPR spectra have been investigated for NCS05-Med and NCS05-Red samples (Figure 6).

The NCM05-Med signal is not constant before and after the $\mathrm{g}=2$ line, suggesting the presence of a broad signal originating from $\mathrm{Fe}^{3+}-\mathrm{Fe}^{3+}$ interactions and overlapping with the isolated $\mathrm{Fe}^{3+}$ signal at $\mathrm{g}=2$ (dashed line in Figure 6).

The signal proportion between $\mathrm{g}=2$ and $\mathrm{g}=4.3$ are inverted comparing to $\mathrm{X}$-band. The dramatic loss of intensity of the $\mathrm{g}=4.3$ signal indicates that rhombic distortion is small relative to Q-band frequency. As a consequence the $\mathrm{g}=2$ signal of isolated paramagnetic species is expected to increase relative to X-band spectra, which is observed: the Q-band signal of the NCS05-Med sample at $g=2$ is a relatively sharp and intense signal. In the NCS05-Med sample, about 80 to $90 \%$ of the integrated signal is at $\mathrm{g}=2$ whereas 10 to $20 \%$ is at $\mathrm{g}=4.3$. The remaining $\mathrm{g}=4.3$ weak line demonstrates the presence of a low amount of sites with a rhombic distortion. This confirms that $\mathrm{Fe}^{3+}$ plays a network former role with a limited distribution of the polarization of the oxygens in polymerized glasses and that only a few sites show a rhombic distortion.

In the Q-band spectrum of NCS05-Red (Figure 6), the absence of $g=4.3$ signal suggests a less distorted environment for $\mathrm{Fe}^{3+}$ in reduced than in medium samples. The numerous $\mathrm{Fe}^{3+}$ peaks between 1000 and $1300 \mathrm{mT}$ may be related to a lower site distribution, in agreement with the splitting observed at $\mathrm{g}=4.3$ in X-band (inset of Figures 3 and 4). The low-field signal (below $500 \mathrm{mT}$ ) confirms the presence of a few ppm of metallic Fe, already detected at X-band.

\subsection{Evidence of non-random distribution of $\mathrm{Fe}^{3+}$}

As observed with optical absorption spectroscopy (Figure 3) and X-band EPR (Figures 7a, 7b and 7c), NCMS shows an intermediate behavior between NCS and NMS. Surprisingly, the NCMS05-Med spectrum does not correspond to an average of the spectra of NCS05-Med and NMS05-Med, meaning that the environment of $\mathrm{Fe}^{3+}$ in NCMS looks more like $\mathrm{Fe}^{3+}$ in NCS than in NMS. This indicates that $\mathrm{Fe}^{3+}$ sites are not randomly and homogeneously distributed into the glass matrix as they are sensing a more calcic than magnesian environment. A similar preferential coupling between transition elements and alkalis/alkaline earths has been observed for $\mathrm{Cr}^{3+}$ ions in soda-lime glasses, where $\mathrm{Cr}^{3+}$ shows a 
preference for a Na-rich environment.[47]

\subsection{Site distortion}

The redox state of the samples investigated influences the EPR spectra (Figure 8). The almost linear evolution of $\mathrm{I}_{\mathrm{pp}}$ and $\Delta \mathrm{H}_{\mathrm{pp}}$ with redox for a fixed total iron content $\left(0.5 \mathrm{wt} \%\right.$ of $\left.\mathrm{Fe}_{2} \mathrm{O}_{3}\right)$ is similar to the variation obtained by changing the total iron content at a given redox.[26] This indicates a linear variation of the $\mathrm{Fe}^{3+}$ concentration with the redox values in the glass elaboration conditions used. The quasi-linearity of the product $\mathrm{I}_{\mathrm{pp}} \Delta \mathrm{H}_{\mathrm{pp}}$ (Figure 8c) confirms the Lorentzian shape expected for the $\mathrm{g}=4.3$ signal of $\mathrm{Fe}^{3+}$ in diluted glasses.[26] Increasing $\mathrm{Fe}^{3+}$ concentration leads to a broadening of the EPR signal, which is indicative of a larger distribution including isolated $\mathrm{Fe}^{3+}$ sites with a smaller average distortion. On the contrary, at low $\mathrm{Fe}^{3+}$-content, site distribution is smaller (discrete EPR transitions at $\mathrm{g}=4.3$ compared to oxidized sample without split signal) with a predominance of distorted sites (smaller $\Delta \mathrm{H}_{\mathrm{pp}}$ ). However, the Q-band EPR signal at $\mathrm{g}=4.3$ (Figure 6) indicates that only a small amount of rhombically distorted sites are present in NCS05-Med while there is no resonance in NCS05-Red. Despite the average sites appear more distorted in NCS05-Red, NCS05Med presents sites with a stronger rhombic distortion.

In Q-band, the integrated EPR signal at $\mathrm{g}=4.3$ participates in less than $10 \%$ of the total integrated EPR signal, while it represents $50-60 \%$ in X-band. The trend of the $\mathrm{g}=2$ signal to increase at Q-band relatively to $\mathrm{X}$-band, in which the $\mathrm{g}=4.3$ signal is dominating, is in accordance with previous observations [42] on borate glasses. However, in the sodium-alkaline earth-silicate glasses investigated, the low intensity of the Q-band signal at $\mathrm{g}=4.3$ suggests a smaller proportion of rhombically distorted $\mathrm{Fe}^{3+}$ sites than in lithium-borate glasses.

The nature of the alkaline earth cations has a smaller effect on $\mathrm{I}_{\mathrm{pp}}$ and $\Delta \mathrm{H}_{\mathrm{pp}}$ than the redox. Nevertheless, Mg-containing samples show weaker and broader $g=4.3$ signals. Whatever the redox, the larger linewidth of the $g=4.3$ signal (Figures $7 \mathrm{~b}$ and $8 \mathrm{~b}$ ) for NMS samples compared to NCS samples reflects a decrease of the rhombic distortion of $\mathrm{Fe}^{3+}$ sites (i.e. lower value of $\lambda=\mathrm{E} / \mathrm{D}$ ). [26] $\mathrm{A}$ lower rhombic distortion is supported by the increase of the signal associated to axially distorted sites at $g=8$ (Figure 7a) and $g=2$ (Figure 7c). Due to smaller coordination numbers, 4-fold sites are indeed less subject to distortion. This effect is consistent with the increase of the concentration of tetrahedral sites in $\mathrm{Mg}$-bearing glasses compared to Ca-bearing glasses, with lower average coordination number for $\mathrm{Fe}^{3+}$ in soda-magnesia glasses ( 4.5) than in soda-lime glasses ( 5.0).[48] This is supported by our optical absorption data (Figure 3) suggesting an increase of the $25500 \mathrm{~cm}^{-1}$ contribution (attributed to 5 -fold $\mathrm{Fe}^{3+}$ ) and a decrease of the $26300 \mathrm{~cm}^{-1}$ contribution (attributed to tetrahedral $\left.\mathrm{Fe}^{3+}\right)$.

\subsection{Clustering vs isolated sites}


Clustering effects may be evaluated by the ratio between the intensity of the transitions linked to isolated and clustered $\mathrm{Fe}^{3+}$ at $\mathrm{g}=4.3$ and $\mathrm{g}=2$, respectively (Figure 9). The reduced samples have the lowest $\mathrm{I}_{\mathrm{pp}}(\mathrm{g}=4.3) / \mathrm{I}_{\mathrm{pp}}(\mathrm{g}=2)$ ratio, suggesting that they contain a higher proportion of $\mathrm{Fe}^{3+}$ involved in clusters than more oxidized samples. This interpretation is corroborated by the antiferromagnetic origin of the $g=2$ signal in reduced samples (Figure 5). According to previous articles that studied the effect of total Fe-content in sodium-silicate glasses, the reduced samples investigated here have a $\mathrm{g}=2$ signal shape similar to the one observed at higher iron content $\left(\left[\mathrm{Fe}_{2} \mathrm{O}_{3}\right]>1 \mathrm{~mol} \%\right) \cdot[17,18]$ In these high Fe-glasses, $\mathrm{Fe}^{3+}$-rich clusters have been shown by optical absorption and Mössbauer spectroscopic properties [49] and confirmed by neutron diffraction and numerical simulations. [50] The present study shows that, in reduced samples, residual $\mathrm{Fe}^{3+}$ tends to segregate, with an EPR signature similar to that in concentrated glasses. In minerals, clusters involve ${ }^{[6]} \mathrm{Fe}^{3+}$ cations.[51] By analogy, iron clusters in glasses would be favored by $\mathrm{Fe}^{3+}$ located in 5-fold or 6-fold coordinated sites: this indicates that reduced glasses contain a higher proportion of ${ }^{[5]} \mathrm{Fe}^{3+}$ and/or ${ }^{[6]} \mathrm{Fe}^{3+}$ than the corresponding oxidized glasses. Indeed, the linkage between tetrahedral cation sites is unfavored energetically, as predicted by the Lowenstein exclusion rule[52] leading to the formation of oxygen triclusters. Whatever the redox, the ratio $I_{p p}(g=4.3) / I_{p p}(g=2)$ decreases when $\mathrm{Mg}$ is added, suggesting that the NMS05 glass contains a higher proportion of $\mathrm{Fe}^{3+}$ clusters than the NCS05 glass. This result indicates that smaller alkaline-earth ions promote $\mathrm{Fe}^{3+}$ cluster formation, in agreement agrees with previous studies.[53]

\section{Conclusions}

Complementary data from X- and Q-band EPR at variable temperature, and optical absorption spectroscopy provide unique information on the structural behavior of $\mathrm{Fe}^{3+}$ in sodium-alkaline earth silicate glasses as a function of redox (oxidized glasses with $\mathrm{Fe}^{2+} / \mathrm{Fe}_{\mathrm{tot}} \approx 5 \%$, medium glasses with $\mathrm{Fe}^{2+} / \mathrm{Fe}_{\mathrm{tot}} \approx 25 \%$ and reduced glasses with $\mathrm{Fe}^{2+} / \mathrm{Fe}_{\mathrm{tot}} \approx 99 \%$ ) and glass composition. In medium and oxidized glasses, a majority of $\mathrm{Fe}^{3+}$ occurs in tetrahedral sites with a minority of 5-fold coordinated sites. These sites are partitioned between isolated and clustered sites. There is a significant compositional dependence of the spectroscopic properties of sodium-alkaline earth silicate glasses. Changing $\mathrm{Ca}$ to $\mathrm{Mg}$ increases the amount of tetrahedral $\mathrm{Fe}^{3+}$ sites and decreases their distortion, which modifies glass optical transmission in the visible. It also reduces the amount of isolated rhombic $\mathrm{Fe}^{3+}$ sites and promotes the formation of Fe-rich clusters. These compositional effects confirm the nonhomogeneous structure of silicate glasses.

The site distortion of the isolated sites has been evaluated by X- and Q-band EPR at helium and room temperature. The Fe-redox state has an important effect on the local environment of $\mathrm{Fe}^{3+}$. In medium and oxidized glasses, $\mathrm{Fe}^{3+}$ sites are mostly isolated with a broad distribution centered on a modest rhombic distortion, but including a small proportion of rhombically distorted $\mathrm{Fe}^{3+}$ sites. This indicates a high proportion of ${ }^{[4]} \mathrm{Fe}^{3+}$ sites. Reduced glasses show a larger contribution of Fe-rich 
clusters, with a possible presence of metallic Fe. An original feature is the presence of rhombically distorted, isolated $\mathrm{Fe}^{3+}$ sites with a narrow site distribution, which is consistent with the presence of higher coordination numbers. The spectroscopic behavior of $\mathrm{Fe}^{3+}$ in these reduced glasses indicates an original surrounding, which is hidden within a broader site distribution at higher $\mathrm{Fe}^{3+}$-content in the medium and oxidized glasses.

\section{Acknowledgments}

The authors would like to thank AGC for sample synthesis and technical support, Jürgen Von Bardeleben (INSP, University Pierre \& Marie Curie) and Maxime Guillaumet (IMPMC, University Pierre $\&$ Marie Curie) for their help in data acquisition. This work was supported by ANRT, under the CIFRE Contract 2012/0640 and by AGC.

\section{References}

[1] W. Johnston, J. Am. Ceram. Soc. 47 (1964) 198-201.

[2] B.O. Mysen, P. Richet, Silicate Glasses and Melts: Properties and Structure, Elsevier, 2005 .

[3] V.C. Kress, I.S.E. Carmichael, Geochim. Cosmochim. Acta 53 (1989) 2883-2892.

[4] R.G. Burns, Mineralogical applications of crystal field theory, Cambridge University Press, 1993.

[5] K. Sakaguchi, T. Uchino, J. Non-Cryst. Solids 353 (2007) 4753-4761.

[6] D. Möncke, D. Ehrt, Opt. Mater. 25 (2004) 425-437.

[7] G. Calas, J. Petiau, Bull. Minéralogie 106 (1983) 33-55.

[8] G. Calas, J. Petiau, Solid State Commun. 48 (1983) 625-629.

[9] C. Weigel, L. Cormier, G. Calas, L. Galoisy, D.T. Bowron, Phys. Rev. B 78 (2008).

[10]F. Farges, Y. Lefrère, S. Rossano, A. Berthereau, G. Calas, G.E. Brown Jr., J. NonCryst. Solids 344 (2004) 176-188.

[11] W.E. Jackson, F. Farges, M. Yeager, P.A. Mabrouk, S. Rossano, G.A. Waychunas, E.I. Solomon, G.E. Brown Jr, Geochim. Cosmochim. Acta 69 (2005) 4315-4332.

[12] B. Guillot, N. Sator, Geochim. Cosmochim. Acta 71 (2007) 1249-1265. 
[13] T. Castner, G.S. Newell, W.C. Holton, C.P. Slichter, J. Chem. Phys. 32 (1960) 668673.

[14] R.D. Dowsing, J.F. Gibson, J. Chem. Phys. 50 (1969) 294-303.

[15] C.R. Kurkjian, E.A. Sigety, Phys. Chem. Glas. 9 (1968) 73-83.

[16] A. Montenero, M. Friggeri, D.C. Giori, N. Belkhiria, L.D. Pye, J. Non-Cryst. Solids 84 (1986) 45-60.

[17] E.S. Dunaeva, I.A. Uspenskaya, K.V. Pokholok, V.V. Minin, N.N. Efimov, E.A. Ugolkova, E. Brunet, J. Non-Cryst. Solids 358 (2012) 3089-3095.

[18] C. Rüssel, Glastech. Berichte-Glass Sci. Technol. 66 (1993) 68-75.

[19] D.L. Griscom, J. Non-Cryst. Solids 40 (1980) 211-272.

[20] D.W. Moon, J.M. Aitken, R.K. MacCrone, G.S. Cieloszyk, Phys. Chem. Glas. 16 (1975) 91-102.

[21] A.K. Boudalis, Y. Sanakis, F. Dahan, M. Hendrich, J.-P. Tuchagues, Inorg. Chem. 45 (2006) 443-453.

[22] S. Aime, B. Bergamasco, D. Biglino, G. Digilio, M. Fasano, E. Giamello, L. Lopiano, Biochim. Biophys. Acta BBA - Mol. Basis Dis. 1361 (1997) 49-58.

[23] Y.A. Koksharov, S.P. Gubin, I.D. Kosobudsky, M. Beltran, Y. Khodorkovsky, A.M. Tishin, J. Appl. Phys. 88 (2000) 1587.

[24] M. Duttine, G. Villeneuve, G. Poupeau, A.M. Rossi, R.B. Scorzelli, J. Non-Cryst. Solids 323 (2003) 193-199.

[25]A. Abragam, B. Bleaney, Electron Paramagnetic Resonance of Transition Ions, Clarendon P., 1970.

[26] A. Elvers, R. Weissmann, Glass Sci. Technol. 74 (2001) 32-38.

[27] B. Camara, J. Phys. Colloq. 43 (1982) C9-165-C9-168.

[28] R. Berger, J. Kliava, E.-M. Yahiaoui, J.-C. Bissey, P.K. Zinsou, P. Béziade, J. NonCryst. Solids 180 (1995) 151-163. 
[29] C14 Committee, Test Methods for Chemical Analysis of Soda-Lime and Borosilicate Glass, ASTM International, 2011.

[30] T.T. Volotinen, J.M. Parker, P.A. Bingham, Phys. Chem. Glas. - Eur. J. Glass Sci. Technol. Part B 49 (2008) 258-270.

[31] G.H. Faye, Can. Mineral. 10 (1969) 112-117.

[32] K. Langer, G. Smith, U. Hålenius, Phys. Chem. Miner. 8 (1982) 143-145.

[33] R.M. Abu-Eid, K. Langer, F. Seifert, Phys. Chem. Miner. 3 (1978) 271-289.

[34] C. Lin, Bull Miner. 104 (1981) 218-222.

[35] P.G. Manning, Can. Mineral. 10 (1970) 677-688.

[36] P. Levitz, D. Bonnin, G. Calas, A. Legrand, J. Phys. E-Sci. Instrum. 13 (1980) $427-$ 432.

[37] S. Rossano, A. Ramos, J.-M. Delaye, S. Creux, A. Filipponi, C. Brouder, G. Calas, EPL Europhys. Lett. 49 (2000) 597.

[38] T.E. Westre, P. Kennepohl, J.G. DeWitt, B. Hedman, K.O. Hodgson, E.I. Solomon, J. Am. Chem. Soc. 119 (1997) 6297-6314.

[39] L.B. Glebov, E.N. Boulos, L.N. Glebova, T.V. Smirnova, in:, Proc. 18th Int. Congr. Glass, San Francisco, USA, 1998, pp. 71-76.

[40] G.R. Rossman, M.N. Taran, Am. Mineral. 86 (2001) 896-903.

[41] K. Schmetzer, M. Burford, L. Kiefert, H.J. Bernhardt, Gems Gemol. 39 (2003) 32-37.

[42] E. Yahiaoui, R. Berger, Y. Servant, J. Kliava, L. Dugunov, A. Mednis, J. Phys.Condens. Matter 6 (1994) 9415-9428.

[43] A.F. Reid, H.K. Perkins, M.J. Sienko, Inorg. Chem. 7 (1968) 119-126.

[44] J.C.J. Bart, N. Burriesci, F. Cariati, S. Cavallaro, N. Giordano, M. Petrera, Bull Miner. 105 (1982) 43-50.

[45] I. Ardelean, M. Peteanu, S. Filip, V. Simon, G. Gyorffy, Solid State Commun. 102 (1997) 341-346. 
[46] I. Ardelean, P. Păşcuţă, L.V. Giurgiu, Int. J. Mod. Phys. B 17 (2003) 3049-3056.

[47] O. Villain, L. Galoisy, G. Calas, J. Non-Cryst. Solids 356 (2010) 2228-2234.

[48] P.A. Bingham, O.M. Hannant, N. Reeves-McLaren, M.C. Stennett, R.J. Hand, J. NonCryst. Solids 387 (2014) 47-56.

[49] P.A. Bingham, J.M. Parker, T. Searle, J.M. Williams, K. Fyles, J. Non-Cryst. Solids 253 (1999) 203-209.

[50] C. Weigel, L. Cormier, G. Calas, L. Galoisy, D.T. Bowron, J. Non-Cryst. Solids 354 (2008) 5378-5385.

[51] R.G. Burns, Annu. Rev. Earth Planet. Sci. 9 (1981) 345-383.

[52] J.-M. Delaye, L. Cormier, D. Ghaleb, G. Calas, J. Non-Cryst. Solids 293-295 (2001) 290-296.

[53] P.A. Bingham, J.M. Parker, T. Searle, J.M. Williams, I. Smith, Comptes Rendus Chim. 5 (2002) 787-796. 
Table 1: Redox measurements: $\mathrm{Fe}^{2+} / \mathrm{Fe}_{\text {tot }}$ (in \%), of the 0.5 wt\% $\mathrm{Fe}_{2} \mathrm{O}_{3}$ doped silicates from wet chemical analysis (3\% uncertainty).

\begin{tabular}{lccc}
\hline Sample name & Oxidized (Ox) & Medium (Med) & Reduced (Red) \\
\hline \hline NCS05 & 6 & 28 & 99 \\
NCMS05 & 5 & 25 & 99 \\
NMS05 & 6 & 24 & 99 \\
\hline
\end{tabular}

Table 2: Electron microprobe analysis (EMPA) measurements (in wt\%) and nominal composition (converted in wt\%), standard deviations of each element are in parenthesis.

\begin{tabular}{lrrrrrr}
\hline & $\mathrm{SiO}_{2}$ & $\mathrm{Na}_{2} \mathrm{O}$ & $\mathrm{CaO}$ & $\mathrm{MgO}$ & $\mathrm{Fe}_{2} \mathrm{O}_{3}$ & Total \\
\hline \hline NCS05-Med & $73.89(0.73)$ & $15.73(0.37)$ & $9.47(0.23)$ & $0.01(0.01)$ & $0.52(0.02)$ & $99.61(0.56)$ \\
NCS05-Ox & $75.43(0.50)$ & $15.99(0.40)$ & $8.26(0.31)$ & $0.00(0.00)$ & $0.54(0.004)$ & $100.23(0.43)$ \\
NCS05-Red & $74.32(0.80)$ & $15.61(0.44)$ & $9.35(0.33)$ & $0.00(0.00)$ & $0.51(0.02)$ & $99.79(0.58)$ \\
Nominal-NCS05 & 73.75 & 16.45 & 9.30 & 0.00 & 0.50 & 100.00 \\
\hline NCMS05-Med & $75.78(1.18)$ & $16.05(0.51)$ & $4.54(0.23)$ & $3.31(0.31)$ & $0.52(0.03)$ & $100.17(0.84)$ \\
NCMS05-Ox & $77.32(0.56)$ & $15.89(0.10)$ & $4.43(0.17)$ & $2.84(0.10)$ & $0.52(0.003)$ & $100.99(0.59)$ \\
NCMS05-Red & $74.50(0.68)$ & $16.37(0.65)$ & $4.97(0.16)$ & $3.67(0.16)$ & $0.55(0.04)$ & $100.05(0.61)$ \\
Nominal-NCMS05 & 74.73 & 16.67 & 4.71 & 3.39 & 0.50 & 100.00 \\
\hline NMS05-Med & $75.62(0.96)$ & $16.77(0.43)$ & $0.01(0.01)$ & $7.03(0.21)$ & $0.51(0.03)$ & $99.93(0.88)$ \\
NMS05-Ox & $75.69(0.47)$ & $17.61(0.28)$ & $0.00(0.00)$ & $7.00(0.16)$ & $0.56(0.01)$ & $100.87(0.46)$ \\
NMS05-Red & $75.45(0.91)$ & $17.04(0.37)$ & $0.02(0.03)$ & $7.19(0.20)$ & $0.52(0.02)$ & $100.19(0.88)$ \\
Nominal-NMS05 & 75.74 & 16.89 & 0.00 & 6.87 & 0.50 & 100.00 \\
\hline
\end{tabular}


Table 3: Fitting parameters and corresponding spin forbidden d-d transitions attribution for the absorbance peaks of Fe ${ }^{3+}$ ions in the NCS05-Med glass.

\begin{tabular}{|c|c|c|c|c|}
\hline Peak \# & $\begin{array}{l}\text { Peak position } \\
\left(\mathrm{cm}^{-1}\right)\end{array}$ & $\begin{array}{l}\text { Full width at half } \\
\text { maximum } \\
\left(\mathrm{cm}^{-1}\right)\end{array}$ & $\begin{array}{l}\text { Peak height } \\
\left(\mathrm{L} \cdot \mathrm{mol}^{-1} \cdot \mathrm{cm}^{-1}\right)\end{array}$ & Assignments \\
\hline 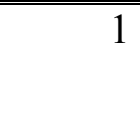 & $21200 \pm 200$ & $2360 \pm 300$ & $0.13 \pm 0.02$ & $\begin{array}{l}{ }^{[4]} \mathrm{Fe}^{3+},{ }^{6} \mathrm{~A}_{1}(\mathrm{~S}) \rightarrow{ }^{4} \mathrm{~T}_{2}(\mathrm{G}) \\
{ }^{\left[{ }^{3}\right.} \mathrm{Fe}^{3+},{ }^{6} \mathrm{~A}_{1}(\mathrm{~S}) \rightarrow{ }^{4} \mathrm{~A}_{1},{ }^{4} \mathrm{E}(\mathrm{G})\end{array}$ \\
\hline 2 & $22810 \pm 40$ & $1450 \pm 70$ & $0.46 \pm 0.02$ & ${ }^{[4]} \mathrm{Fe}^{3+},{ }^{6} \mathrm{~A}_{1}(\mathrm{~S}) \rightarrow{ }^{4} \mathrm{~A}_{1}{ }^{4} \mathrm{E}(\mathrm{G})$ \\
\hline 3 & $23980 \pm 30$ & $1370 \pm 100$ & $0.38 \pm 0.02$ & ${ }^{[4]} \mathrm{Fe}^{3+},{ }^{6} \mathrm{~A}_{1}(\mathrm{~S}) \rightarrow{ }^{4} \mathrm{~T}_{2}(\mathrm{D})$ \\
\hline 4 & $25600 \pm 30$ & $1030 \pm 75$ & $0.42 \pm 0.02$ & ${ }^{[5]} \mathrm{Fe}^{3+},{ }^{6} \mathrm{~A}_{1}(\mathrm{~S}) \rightarrow{ }^{4} \mathrm{~T}_{2}(\mathrm{D})$ \\
\hline 5 & $26340 \pm 10$ & $910 \pm 10$ & $1.71 \pm 0.02$ & ${ }^{[4]} \mathrm{Fe}^{3+},{ }^{6} \mathrm{~A}_{1}(\mathrm{~S}) \rightarrow{ }^{4} \mathrm{E}(\mathrm{D})$ \\
\hline 6 & $27190 \pm 50$ & $540 \pm 100$ & $0.11 \pm 0.02$ & ${ }^{[5,6]} \mathrm{Fe}^{3+},{ }^{6} \mathrm{~A}_{1(\mathrm{~g})}(\mathrm{S}) \rightarrow{ }^{4} \mathrm{E}_{(\mathrm{g})}(\mathrm{D})$ \\
\hline 7 & $36400 \pm 300$ & $8050 \pm 500$ & $900 \pm 30$ & $\mathrm{OMCT} \mathrm{Fe} e^{3+} \rightarrow \mathrm{O}^{2-}$ \\
\hline 8 & $42400 \pm 300$ & $16500 \pm 900$ & $120 \pm 30$ & $\mathrm{OMCT} \mathrm{Fe}^{2+} \rightarrow \mathrm{O}^{2-}$ \\
\hline
\end{tabular}

Table 4: $\mathrm{Fe}^{3+}$ spin forbidden d-d transitions attribution for the absorbance peaks (in $\mathrm{cm}^{-1}$ ) of $3 \mathrm{Fe}$-bearing minerals with different site symmetry and coordination number $(\mathrm{CN})$. Band numbers in parenthesis correspond to the fit of the glass (Table 3).

\begin{tabular}{|c|c|c|c|c|c|c|c|c|}
\hline Name & $\mathrm{CN}$ & Geometry & ${ }^{4} \mathrm{~T}_{1(\mathrm{~g})}(\mathrm{G})$ & ${ }^{4} \mathrm{~T}_{2(\mathrm{~g})}(\mathrm{G})$ & ${ }^{4} \mathrm{~A}_{1(\mathrm{~g})}{ }^{4} \mathrm{E}_{(\mathrm{g})}(\mathrm{G})$ & ${ }^{4} \mathrm{~T}_{2(\mathrm{~g})}(\mathrm{D})$ & ${ }^{4} \mathrm{E}_{(\mathrm{g})}(\mathrm{D})$ & refs \\
\hline Fe-orthoclase & ${ }^{[4]} \mathrm{Fe}^{3+}$ & $\mathrm{T}_{\mathrm{d}}$ & & $\begin{array}{c}20000 \\
(\# 1)\end{array}$ & $22600(\# 2)$ & $\begin{array}{c}23800 \\
(\# 3)\end{array}$ & $\begin{array}{c}26460 \\
(\# 5)\end{array}$ & {$[4,31]$} \\
\hline yoderite & ${ }^{[5]} \mathrm{Fe}^{3+}$ & $\mathrm{C}_{3 \mathrm{v}}$ & & & $\begin{array}{l}20700(\# 1) \\
21500(\# 1)\end{array}$ & $\begin{array}{c}25500 \\
(\# 4)\end{array}$ & $\begin{array}{c}28200 \\
(\# 6)\end{array}$ & {$[32,33]$} \\
\hline andradite & ${ }^{[6]} \mathrm{Fe}^{3+}$ & $\mathrm{C}_{3 \mathrm{i}}\left(\mathrm{S}_{6}\right)$ & 12450 & 16650 & $\begin{array}{l}22700 \\
23000\end{array}$ & 24000 & $\begin{array}{c}27000 \\
(\# 6)\end{array}$ & {$[4,34]$} \\
\hline
\end{tabular}




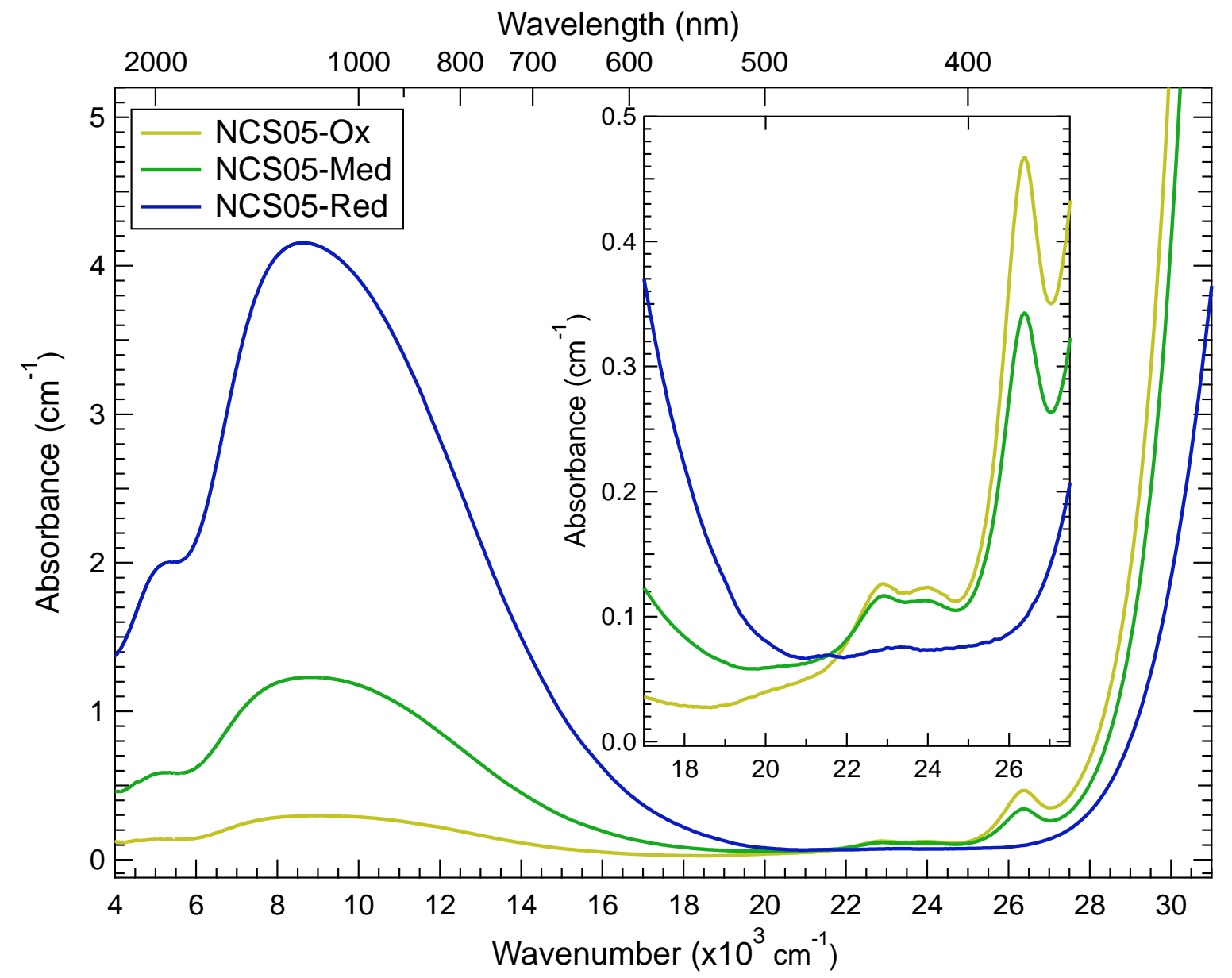

Figure 1: Optical absorption coefficient of the oxidized (NCS05-Ox/yellow), the intermediate redox (NCS05-Med / green) and the reduced (NCSO5-Red / blue) soda-lime-silica glasses. The inset is a zoom on the Fe ${ }^{3+} d$-d transitions range.

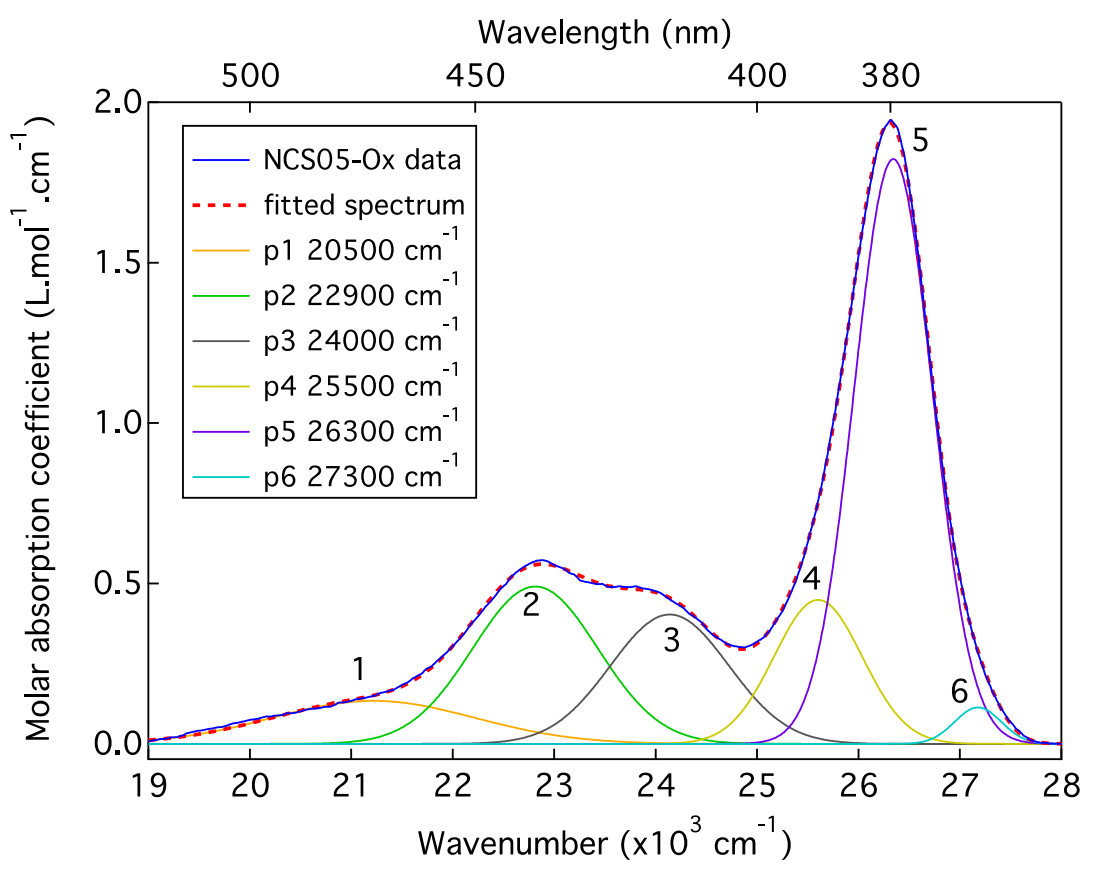

Figure 2: Resulting fit of $\mathrm{Fe}^{3+}$ bands in the soda-lime oxidized glass (NCS05-Ox) after UV-edge removal. The Fe ${ }^{3+}$ bands were fitted with Gaussian functions. The experimental spectrum and the fitted spectrum are shown as a blue line and a red dashed line, respectively. 


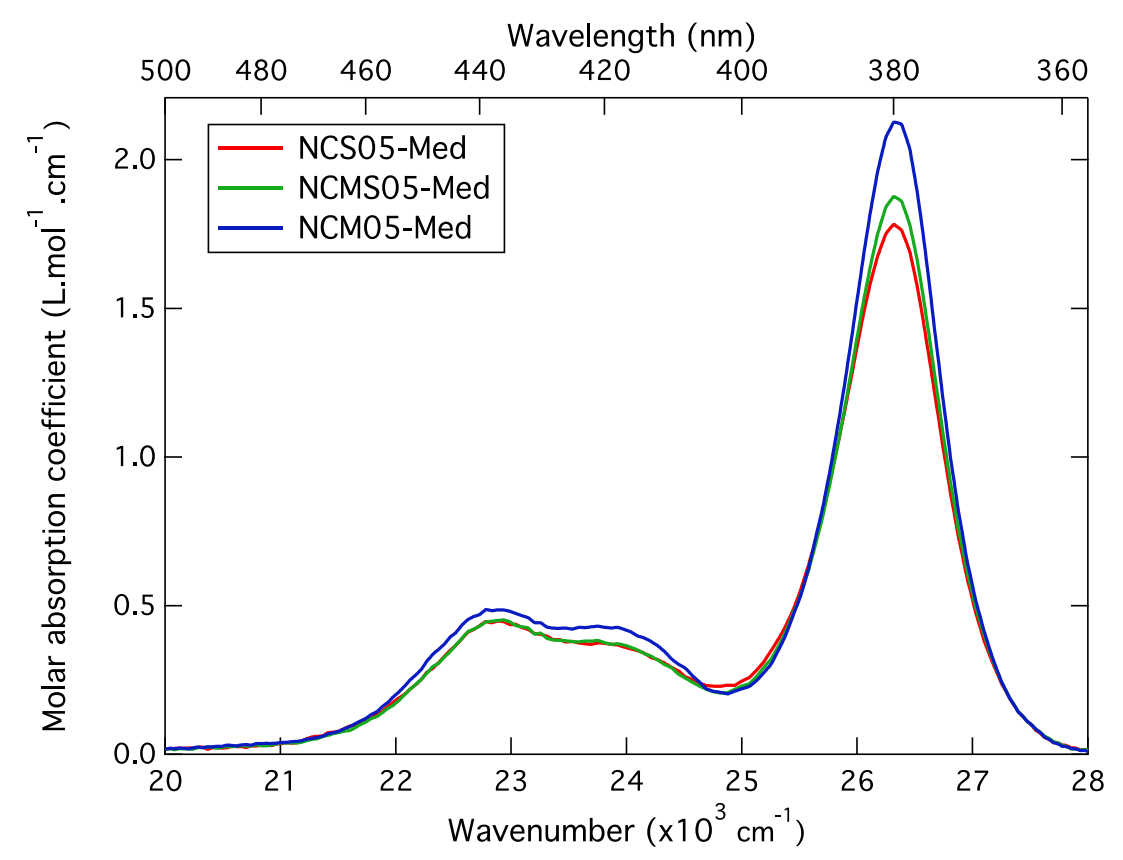

Figure 3: Optical absorption spectra for the three sodium-alkaline earth silicate glasses with a $\mathrm{Fe}^{2+} / \mathrm{Fe}_{\text {tot }}$ ratio around 25\%: NCS05-Med (red), NCMS05-Med (green) and NCM05-Med (blue). UV-edges have been removed using a Gaussian fit of the charge transfer band.

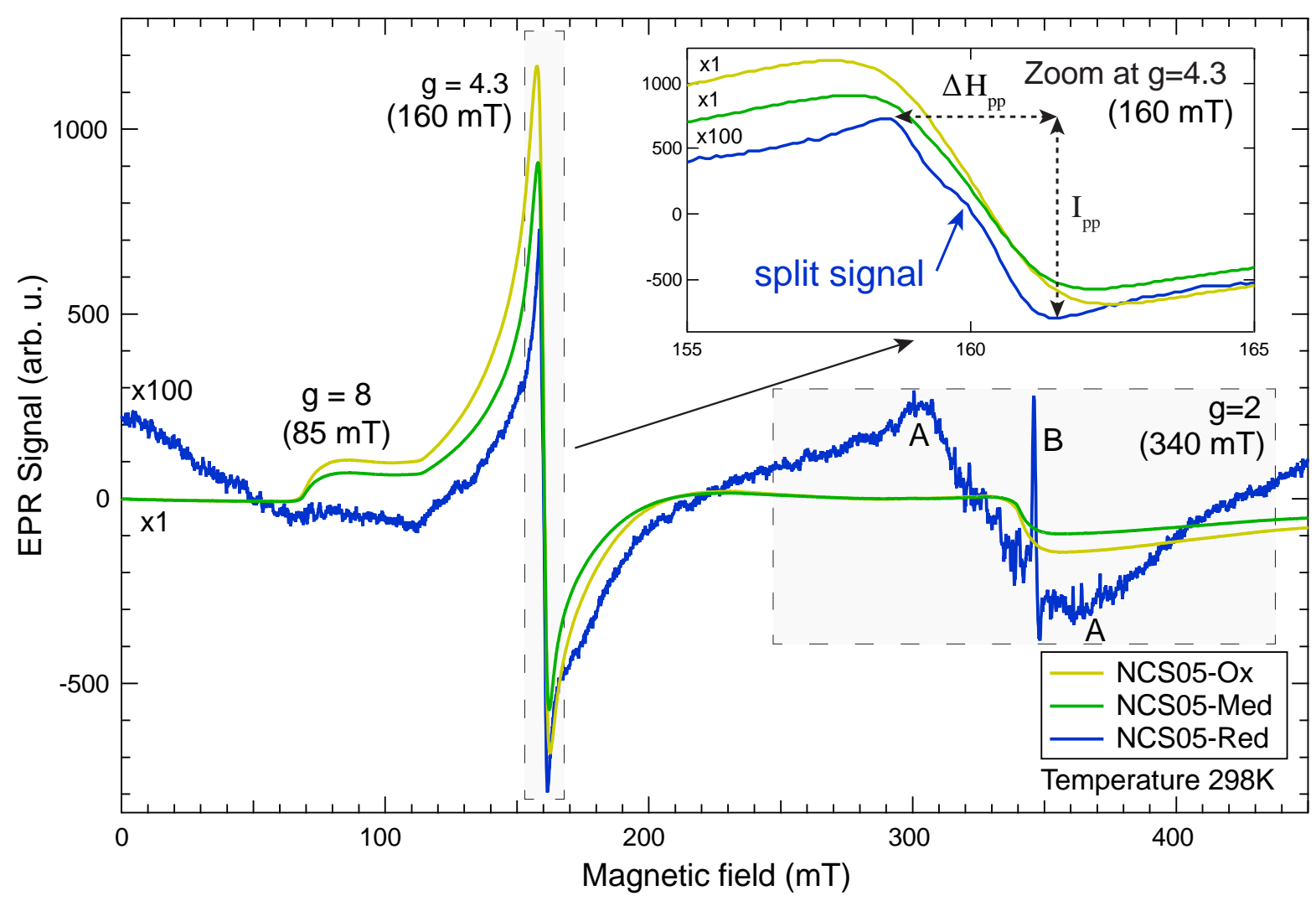

Figure 4: Room temperature X-band EPR signals of a soda-lime-silica glass at three different redox: NCSO5-Ox (yellow / $R=6 \%)$, NCS05-Med (green, $R=28 \%$ ) and NCS05-Red (blue, $R=99 \%)$. The inset is a zoom on the $g=4.3$ line. 


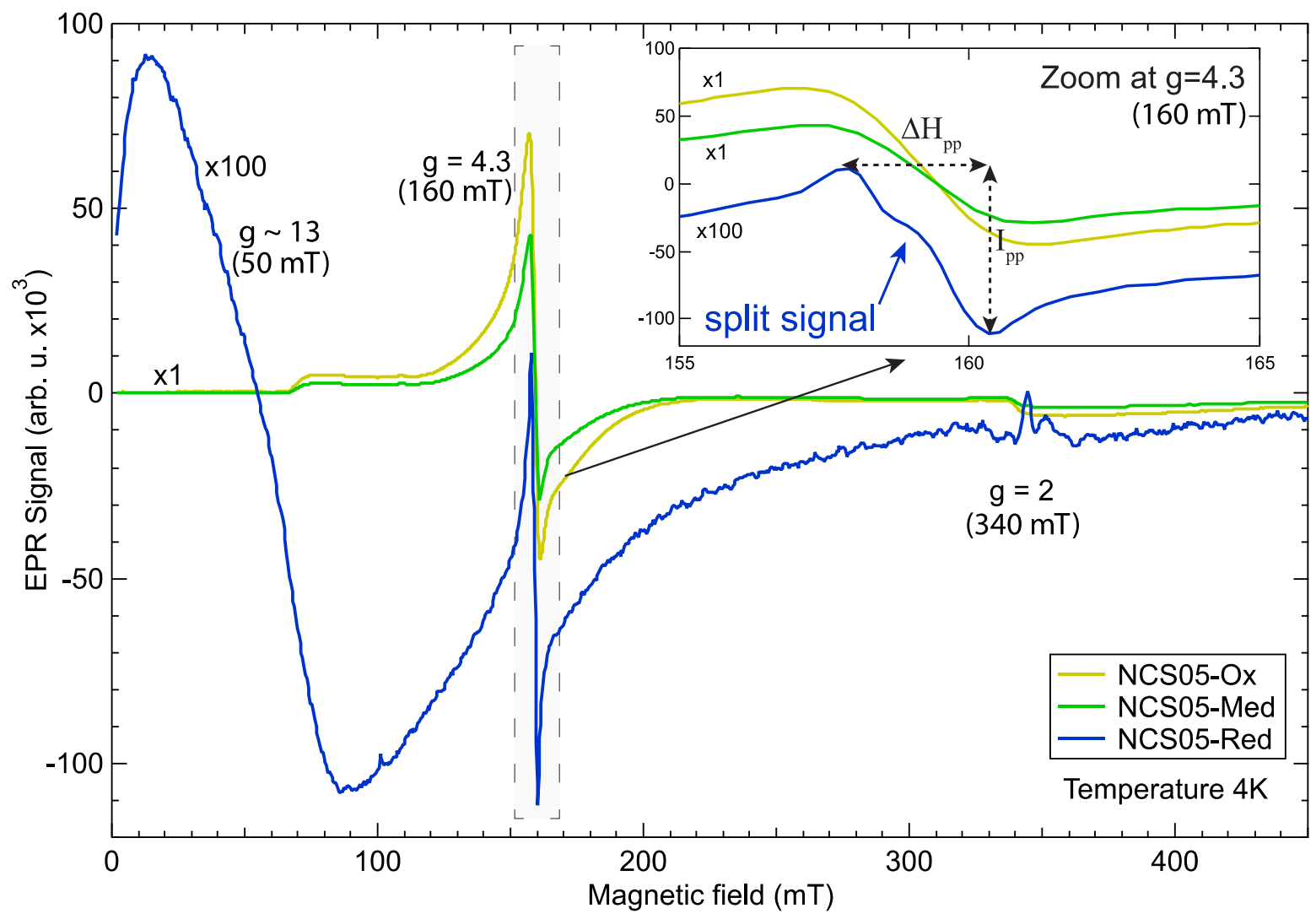

Figure 5: Low-temperature X-band EPR signals of a soda-lime-silica glass at three different redox: NCS05-Ox (yellow / $R=6 \%)$, NCS05-Med (green, $R=28 \%$ ) and NCS05-Red (blue, $R=99 \%)$. The inset is a zoom on the $g=4.3$ line.

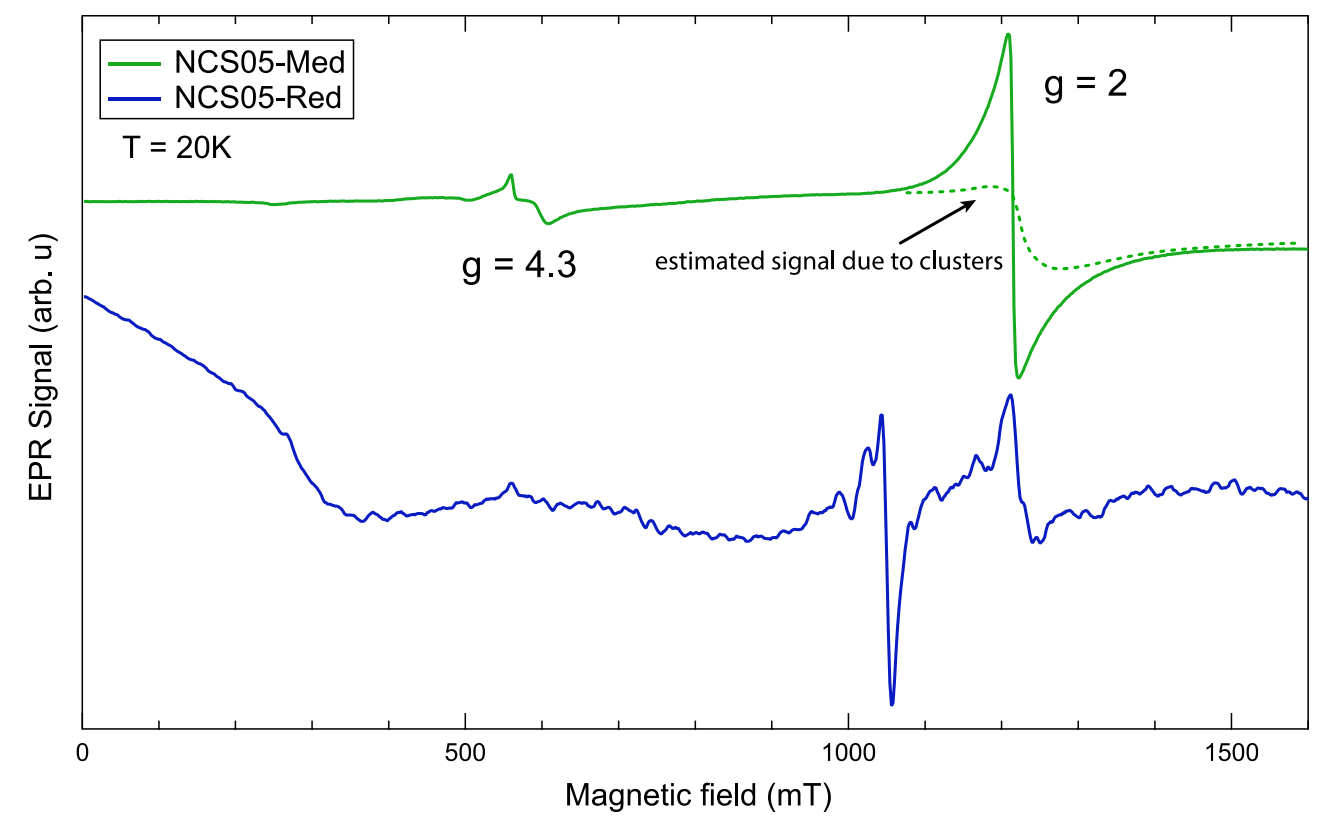

Figure 6: Q-band EPR signals for the samples NCS05-M (green, $R=28 \%$ ) and NCS05-Red (blue, $R=99 \%$ ) for the sodalime glass measured at 20K. The intensities are not normalized. The EPR signal of NCS05-Red has been magnified for clarity reasons. 

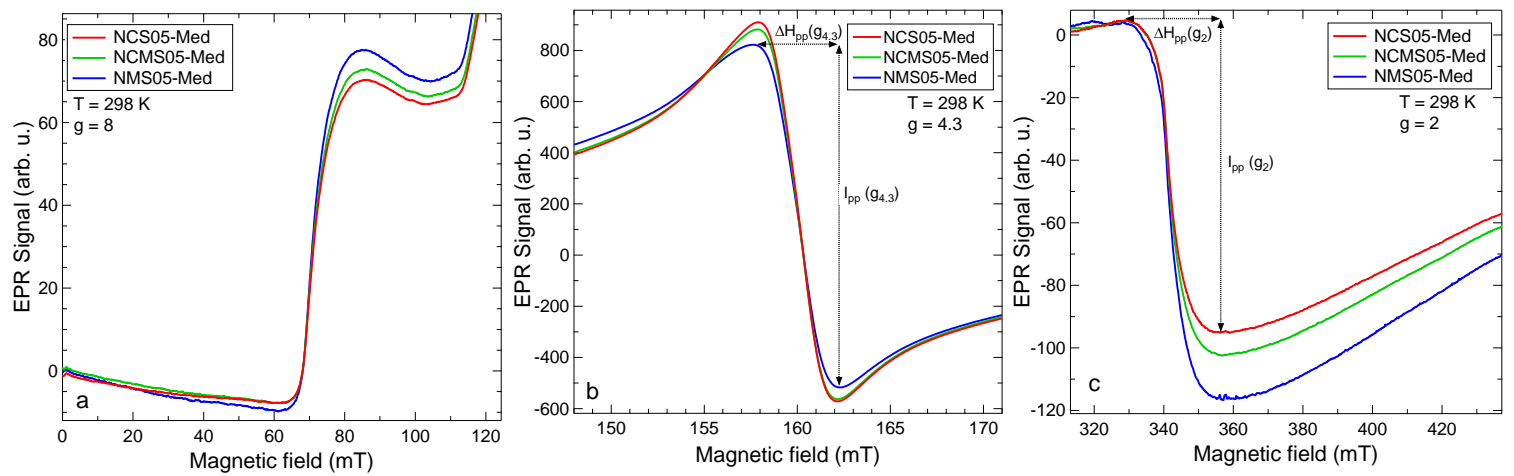

Figure 7: Effects on the X-band EPR signals when $\mathrm{Ca}^{2+}$ is substituted by $\mathrm{Mg}^{2+}$ in the glassy matrix for the three intermediate redox (NCS05-Med (red), NCMS05-Med(green) and NMS05-Med(blue)): (a) increase of the $g=8$ line, (b) decrease and broadening of the $g=4.3$ line and (c) increase of the $g=2$ line.
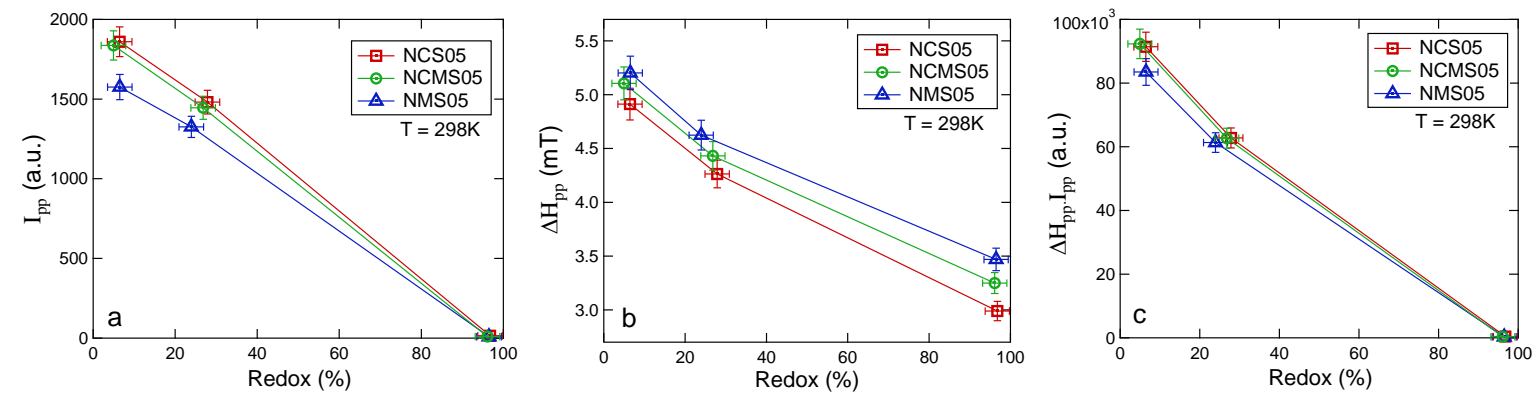

Figure 8: (a) $g=4.3$ peak-to-peak intensity $\left(I_{p p}\right)$, (b) $g=4.3$ peak-to-peak linewidth $\left(\Delta H_{p p}\right)$ and (c) the product of $\Delta H_{p p}$ and $I_{p p}$ as a function of redox $R=F^{2+} / F e_{\text {tot }}$ for the three glass compositions under study: NCS, NCMS and NMS. The lines are a guide for the eyes.

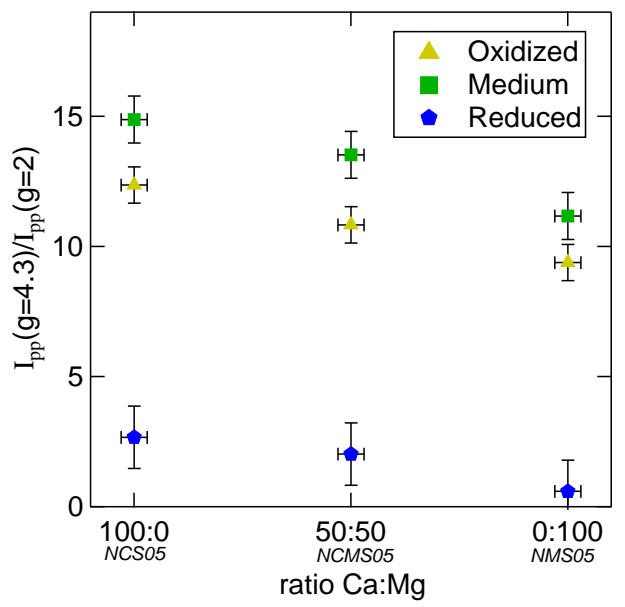

Figure 9: Ratio between the peak-to-peak intensity at $\mathrm{g}=4.3$ and the peak-to-peak intensity at $\mathrm{g}=2$ at $298 \mathrm{~K}$ as a function of the composition of the glassy matrix. The ratio $I_{p p}(g=4.3) / I_{p p}(g=2)$ is correlated to the proportion of Fe ${ }^{3+}$ in isolated distorted sites vs $\mathrm{Fe}^{3+}$ in clusters. 